Check for updates

Cite this: Phys. Chem. Chem. Phys., 2017, 19, 25122

Received 22nd June 2017, Accepted 17th August 2017 DOI: $10.1039 / c 7 c p 04207 h$

rsc.li/pccp

\section{Fast flip-flop of halogenated cobalt bis(dicarbollide) anion in a lipid bilayer membrane}

\author{
Tatyana I. Rokitskaya, (D)*a Irina D. Kosenko, ${ }^{b}$ Igor B. Sivaev, (DD ${ }^{b}$ Yuri N. Antonenko ${ }^{a}$ \\ and Vladimir I. Bregadze ${ }^{b}$
}

\begin{abstract}
Transmembrane translocation (flip-flop) of cobalt bis(dicarbollide) (COSAN) anions, elicited by application of a voltage-jump across the lipid bilayer membrane, manifested itself in monoexponential electrical current transients in the microsecond time scale. Halogenation of COSAN led to multi-fold acceleration of the flip-flop, the effect increasing with the molecular weight of the halogens. The exception was a fluorinated analog which exhibited slowing of the translocation kinetics. Measurements of the fluorescence ratio of the dye di-4-ANEPPS in lipid vesicles showed significant differences in the adsorption of studied hydrophobic anions. Based on these data, it can be concluded that COSAN and COSAN $-F_{2}$ were located on the surface of the lipid membrane in the cisoid conformation increasing the dipole potential of the lipid membrane, while other halogenated COSAN analogs were adsorbed in the transoid conformation. Differences in the flip-flop kinetics of COSAN analogs were attributed to variation in the molecular volume of the anions and their orientation on the membrane surface.
\end{abstract}

\section{Introduction}

Biological membranes are formed by self-assembly of lipid molecules, with their polar head groups exposed to the aqueous environment and their fatty acid tails orientated internally, to create a hydrophobic barrier. In addition to passive diffusion, the permeability of cellular membranes is determined by protein channels and carriers which orchestrate the highly regulated selective transport of ions and metabolites of living cells. In contrast to small inorganic ions, which have poor passive permeability through lipid bilayers, some large organic ions were shown to permeate readily through lipid membranes especially anions with delocalized charge. ${ }^{1-4}$ The anion of cobalt bis(dicarbollide) $\left[3,3^{\prime}-\mathrm{Co}\left(1,2-\mathrm{C}_{2} \mathrm{~B}_{9} \mathrm{H}_{11}\right)_{2}\right]^{-}$(COSAN, Fig. 1 , left structure on the top) consists of the two dicarbollide ligands sandwiching the central cobalt atom and has a dispersed net charge but a hydrophobic surface of two dicarbollide moieties due to weakly polarized B-H and C-H bonds. ${ }^{5,6}$ Surprisingly, COSAN molecules are surface-active ${ }^{7}$ and form a monolayer at the water-air interface with the long axis normal to the surface. ${ }^{8}$ Furthermore cobalt bis(dicarbollide) exhibits a self-association in water ${ }^{9}$ that is comparable to classical micellization. ${ }^{10}$ The origin of the aggregation is still controversial according to the literature. One explanation assumes formation of the intermolecular

\footnotetext{
${ }^{a}$ Belozersky Institute of Physico-Chemical Biology, Lomonosov Moscow State University, Moscow 119991, Russian Federation.

E-mail: rokitskaya@genebee.msu.ru

${ }^{b}$ A. N. Nesmeyanov Institute of Organoelement Compounds, Russian Academy of Sciences, 28 Vavilov Str., 119991, Moscow, Russian Federation
}

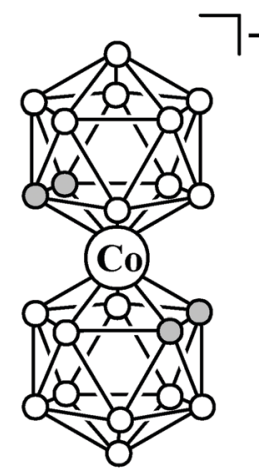

COSAN

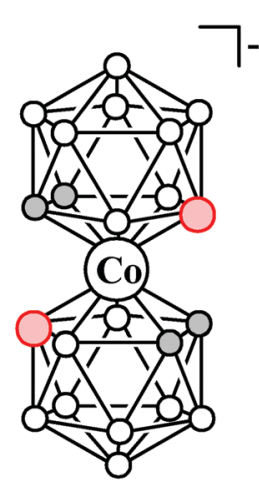

COSAN-X

$$
\mathrm{O}=\mathbf{C H} \quad \mathrm{O}=\mathbf{B H} \quad \mathrm{O}=\mathbf{B X}(\mathrm{X}=\mathbf{F}, \mathbf{C l}, \mathbf{B r}, \mathbf{I})
$$

Fig. 1 Chemical structure of cobalt bis(dicarbollide) (COSAN) and its halogenated analogs studied in the present work.

dihydrogen $\mathrm{B}-\mathrm{H} \cdots \mathrm{H}-\mathrm{C}$ bonds in COSAN solutions that results in their aggregation ${ }^{11}$ whereas the other one is based on nonspecific hydrophobic action. ${ }^{10}$ The combination of hydrophobic semi-cages and the hydrophilic center of COSAN together with the rigid ends $\left(\theta\right.$ shape $\left.^{12}\right)$ makes it form small monolayer vesicles in aqueous solution at a critical concentration of tenths of micromoles with a radius of about $20 \mathrm{~nm}$. It has been shown that the vesicles of COSAN permeate through artificial $^{13}$ and natural ${ }^{14}$ membranes. Iodinated cobalt bis(dicarbollide) $\left[8,8^{\prime}-\mathrm{I}_{2}-\right.$ $\left.3,3^{\prime}-\mathrm{Co}\left(1,2-\mathrm{C}_{2} \mathrm{~B}_{9} \mathrm{H}_{10}\right)_{2}\right]^{-}\left(\mathrm{COSAN}-\mathrm{I}_{2}\right.$, Fig. 1, right structure on the 
top) accumulates in the cells of Dictyostelium ${ }^{14}$ in spite of its lower (compared to COSAN) permeability through artificial lipid membranes. Importantly, the permeation of COSAN is not accompanied by disruption of membrane integrity. The above properties raise a question about the mechanism of the permeability of COSAN and its halogenated derivatives.

The mechanism of the transmembrane translocation of tetraphenylborate and some other hydrophobic anions was studied several decades ago by measuring relaxation of the electrical current across a planar bilayer lipid membrane (BLM) after applying a voltage. ${ }^{3,15}$ The approach can be applied to hydrophobic cations as well ${ }^{16,17}$ provided they possess a high affinity to the lipid-water interface. The transport of hydrophobic ions across the membrane involves three stages: adsorption to the membrane-solution interface, transition through an energy barrier to the opposite interface, and desorption into the aqueous solution. In this work a comparison of the kinetics of the current relaxation of COSAN and their halogenated derivatives allowed us to reveal differences in the process of their transmembrane permeation which were discussed in connection to the molecular volume of the anions and their orientation on the membrane surface.

\section{Materials and methods}

\section{Materials}

Salts of cobalt bis(dicarbollide) $\left.\mathrm{Na}\left[3,3^{\prime}-\mathrm{Co}\left(1,2-\mathrm{C}_{2} \mathrm{~B}_{9} \mathrm{H}_{11}\right)_{2}\right]\right]^{18}$ fluorinated cobalt bis(dicarbollide) $\left(\left(\mathrm{Bu}_{4} \mathrm{~N}\right)\left[8,8^{\prime}-\mathrm{F}_{2}-3,3^{\prime}-\mathrm{Co}(1,2-\right.\right.$ $\left.\left.\left.\mathrm{C}_{2} \mathrm{~B}_{9} \mathrm{H}_{10}\right)_{2}\right]\right),{ }^{19}$ chlorinated cobalt bis(dicarbollide) $\left(\left(\mathrm{Me}_{3} \mathrm{NH}\right)\left[8,8^{\prime}-\right.\right.$ $\left.\left.\mathrm{Cl}_{2}-3,3^{\prime}-\mathrm{Co}\left(1,2-\mathrm{C}_{2} \mathrm{~B}_{9} \mathrm{H}_{10}\right)_{2}\right]\right),{ }^{20}$ brominated cobalt bis(dicarbollide) $\left(\left(\mathrm{Me}_{3} \mathrm{NH}\right)\left[8,8^{\prime}-\mathrm{Br}_{2}-3,3^{\prime}-\mathrm{Co}\left(1,2-\mathrm{C}_{2} \mathrm{~B}_{9} \mathrm{H}_{10}\right)_{2}\right]\right)^{20}$ and iodinated cobalt bis(dicarbollide) $\left(\left(\mathrm{Me}_{4} \mathrm{~N}\right)\left[8,8^{\prime}-\mathrm{I}_{2}-3,3^{\prime}-\mathrm{Co}\left(1,2-\mathrm{C}_{2} \mathrm{~B}_{9} \mathrm{H}_{10}\right)_{2}\right]\right)^{20}$ (Fig. 1) were synthesized as described in the literature.

\section{Planar bilayer}

BLMs were formed from a $2 \%$ solution of diphytanoylphosphatidylcholine (DPhPC) (Avanti Polar Lipids, Alabaster, AL) in $n$-decane on a hole in a Teflon partition separating two compartments of a cell containing aqueous buffer solutions. ${ }^{21}$ The cell with the $0.8 \mathrm{~mm}$ diameter hole was used in current relaxation experiments. Hydrophobic anions were added from stock solutions in ethanol to the bathing solutions at both sides of the BLM and routinely incubated for at least $5 \mathrm{~min}$ with constant stirring. The solution consisted of $100 \mathrm{mM} \mathrm{KCl}$, $10 \mathrm{mM}$ TRIS, and $10 \mathrm{mM}$ MES, $\mathrm{pH}$ 6.0. All experiments were carried out at room temperature $\left(23-25{ }^{\circ} \mathrm{C}\right)$.

In the current relaxation experiments voltages were applied to BLMs by means of a Siglent3408 waveform generator (square form of the waves) with $\mathrm{Ag}-\mathrm{AgCl}$ electrodes placed into the solutions on the two sides of the BLM via agar bridges. The electric current $(I)$ was recorded using a Keithley 428 amplifier (Cleveland, Ohio, USA), digitized using an NI-DAQmx (National Instruments, Austin, TX) and analyzed with a personal computer with the use of WinWCP Strathclyde Electrophysiology Software designed by J. Dempster (University of Strathclyde, UK). At the beginning of each experiment we recorded the capacitance response of the unmodified membrane (control record of the current after applying a voltage wave of the square form). The record in the presence of the studied anions was analyzed after subtraction of the control record.

The electric current was recorded under voltage-clamp conditions by means of a patch-clamp amplifier (Warner Instruments, Hamden, CT, model BC-525C) as stationary current measurements (at a moment of time $>20 \mathrm{~s}$ after application of $5 \mathrm{mV}$ ).

\section{Fluorescence measurements}

4-(2-[6-(Dibutylamino)-2-naphthalenyl]ethenyl)-1-(3-sulfopropyl)pyridinium hydroxide inner salt (di-4-ANEPPS) was obtained from Sigma Aldrich. In vesicles as well as in an aqueous solution dye it showed a single long wavelength fluorescence emission band regardless of the excitation wavelength.

To prepare liposomes, the lipid (10 $\mathrm{mg}$ phosphatidylcholine, eggPC, Avanti Polar Lipids) in a chloroform suspension was dried in a round-bottom flask under a stream of nitrogen. The lipid was then resuspended in $1 \mathrm{ml}$ buffer $(100 \mathrm{mM} \mathrm{KCl}, 30 \mathrm{mM}$ Tris $\mathrm{pH}$ 7.6). The suspension was vortexed and then freeze-thawed three times. Unilamellar liposomes were prepared by extrusion through $0.1 \mu \mathrm{m}$-pore size nucleopore polycarbonate membranes using an Avanti Mini-Extruder. Measurements with the vesicles were performed in the buffer containing $100 \mathrm{mM} \mathrm{KCl,} 30 \mathrm{mM}$ Tris $\mathrm{pH}$ 7.6. In the presence of liposomes (1.3 $\mathrm{mM}$ of lipid in solution), after addition of $0.5 \mu \mathrm{M}$ di-4-ANEPPS 15 min equilibration time was left to allow for dye disaggregation and incorporation into the membranes. The excitation spectrum was measured at emission wavelength $670 \mathrm{~nm} .^{22}$ The ratio of the fluorescence intensities detected at two excitation wavelengths on the blue $(420 \mathrm{~nm})$ and red $(520 \mathrm{~nm})$ flanks of the excitation spectrum was measured as a function of the concentration of the studied hydrophobic anions.

\section{Results}

As shown in the scheme in Fig. 2, the anions of COSAN bind symmetrically to the lipid membrane in the absence of the applied voltage. The application of voltage leads to transmembrane redistribution (flip) of the compounds manifesting itself in the initially high electrical current relaxing to a low level due to a depletion of the compound at one of the interfaces. Fig. 2 shows the COSAN-mediated current relaxation curve upon the application of $50 \mathrm{mV}$ at $t=0$. Low steady-state COSAN current after several milliseconds pointed to a slow binding process from the aqueous phase to the interface compared to the rate of the translocation. At $t=4.2 \mathrm{~ms}$ the potential was switched to zero while the current exhibited a similar relaxation but of the opposite sign (Fig. 2). This process was a result of a return (flop) of COSAN molecules to the initial symmetrical distribution at two sides of the membrane (right part of the scheme in Fig. 2).

Current relaxations mediated by $0.1 \mu \mathrm{M}$ COSAN (black curve), COSAN-F $2\left(\left[8,8^{\prime}-\mathrm{F}_{2}-3,3^{\prime}-\mathrm{Co}\left(1,2-\mathrm{C}_{2} \mathrm{~B}_{9} \mathrm{H}_{10}\right)_{2}\right]^{-}\right.$, pink $), \mathrm{COSAN}^{-\mathrm{Cl}}{ }_{2}\left(\left[8,8^{\prime}-\right.\right.$ $\left.\mathrm{Cl}_{2}-3,3^{\prime}-\mathrm{Co}\left(1,2-\mathrm{C}_{2} \mathrm{~B}_{9} \mathrm{H}_{10}\right)_{2}\right]^{-}$, green $), \mathrm{COSAN}^{-} \mathrm{Br}_{2}\left(\left[8,8^{\prime}-\mathrm{Br}_{2}-3,3^{\prime}-\mathrm{Co}(1,2-\right.\right.$ $\left.\left.\mathrm{C}_{2} \mathrm{~B}_{9} \mathrm{H}_{10}\right)_{2}\right]^{-}$, red) and COSAN-I $\mathrm{I}_{2}$ (blue) are presented in Fig. 2, inset. 


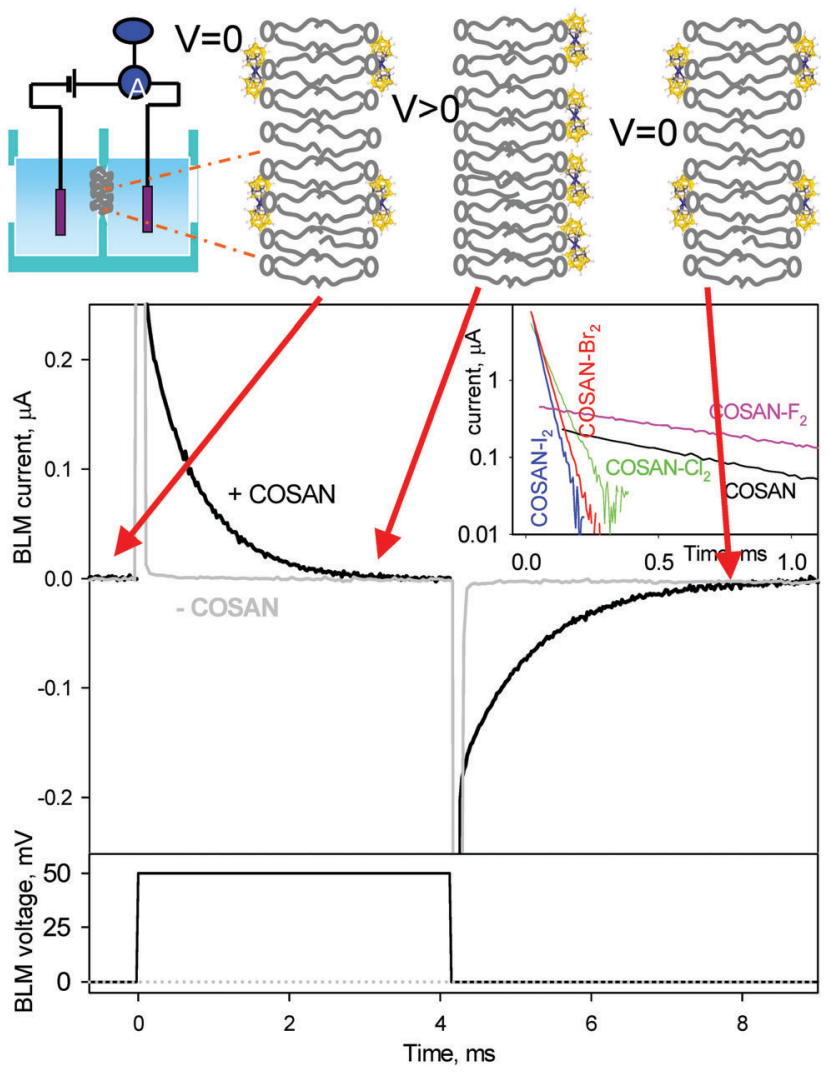

Fig. 2 Top: A scheme of the voltage-jump experiments with a planar lipid bilayer membrane (BLM). Bottom: Time course of electrical current after application of a voltage jump of $V=50 \mathrm{mV}$ (at $t=0$ ) in the presence of $0.1 \mu \mathrm{M}$ of COSAN (black curve). Grey curve represents the control experiment in the absence of cobalt bis(dicarbollide). Voltage was switched off at $t=4.2 \mathrm{~ms}$. Inset: Semi-logariphmic plot of the current relaxation experiments with $\operatorname{COSAN}-\mathrm{I}_{2}$ (blue curve), COSAN-Br 2 (red curve), COSAN- $\mathrm{Cl}_{2}$ (green curve), COSAN- $F_{2}$ (pink curve) and COSAN (black curve) (concentration of all compounds was $0.1 \mu \mathrm{M}$ ).

The BLM was made from diphytanoylphosphatidylcholine (DPhPC) and the voltage-jump was $50 \mathrm{mV}$. The data are represented by straight lines in semi-log plots pointing to their monoexponential character following the equation $I(t)=I_{\infty}+\left(I_{0}-I_{\infty}\right) \cdot \exp (-t / \tau)$. The following $\tau$ values were derived: $660 \mu \mathrm{s}, \mathrm{COSAN} ; 900 \mu \mathrm{s}, \mathrm{COSAN}_{2}$; $50.4 \mu \mathrm{s}, \mathrm{COSAN}_{-\mathrm{Cl}_{2}} ; 36.7 \mu \mathrm{s}, \mathrm{COSAN} \mathrm{Br}_{2}$; and $27.7 \mu \mathrm{s}, \mathrm{COSAN}_{2}$. Therefore, the rate of the flip-flop increased in the series:

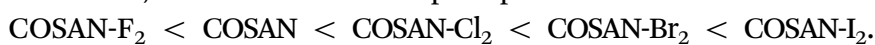
It can be noted that the magnitude of the initial current of halogenated COSAN compounds exceeded substantially that of parent COSAN and COSAN-F 2 (Fig. 2, inset). This finding can be understood bearing in mind that the area below the current relaxation curve corresponded to the total transfer of electrical charge $(Q)$, i.e. the total number of COSAN anions capable to flip upon voltage-jump. Thus, the increase in the rate of the flip must lead to the increase in the amplitude of the initial current assuming a similar surface concentration of the compounds.

The dependence of $Q$ on voltage is shown in Fig. 3A. As expected, $Q$ increased with voltage for all five compounds having a tendency to saturation. The value of $Q$ slightly increased in the
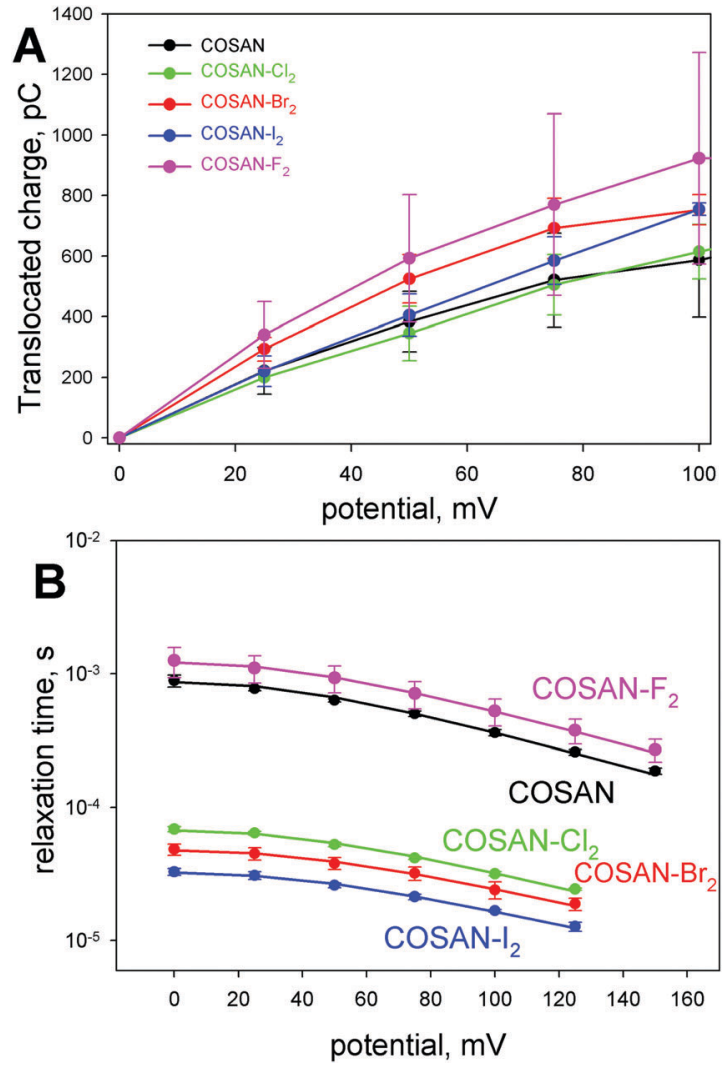

Fig. 3 (A) Voltage-dependence of the transferred electrical charge for $0.1 \mu \mathrm{M}$ COSAN $-I_{2}, \operatorname{COSAN}-\mathrm{Br}_{2}, \operatorname{COSAN}-\mathrm{Cl}_{2}, \operatorname{COSAN}-\mathrm{F}_{2}$ and COSAN in the bathing solution. (B) Voltage dependence of the relaxation time $\tau$ for $\operatorname{COSAN}-\mathrm{I}_{2}, \operatorname{COSAN}-\mathrm{Br}_{2}, \operatorname{COSAN}-\mathrm{Cl}_{2}, \operatorname{COSAN}-\mathrm{F}_{2}$ and $\mathrm{COSAN}$ (concentration of all compounds was $0.1 \mu \mathrm{M}$ ). Solid curves are best fits according to eqn (1).

series: COSAN $\approx$ COSAN-Cl $2 \approx$ COSAN-I ${ }_{2}<{\operatorname{COSAN}-\mathrm{Br}_{2}<}^{2}$ COSAN- $\mathrm{F}_{2}$ apparently not parallel to the increase in affinity to the lipid-water interface. ${ }^{14}$ Panel $\mathrm{B}$ of Fig. 3 displays the dependence of the characteristic time $\tau$ on the BLM voltage $(V)$. As shown for tetraphenylborate and several other anions ${ }^{3,4}$ the dependence of $\tau$ on dimensionless voltage $u=\frac{V}{R T / F}(F, R$ are the Faraday and gas constants, $T$ is absolute temperature, $V$ refers to membrane voltage) can be described by

$$
\tau=\frac{1}{k+2 k_{i} \cosh (\beta z u / 2)}
$$

where $k_{i}$ and $k$ are the translocation rate constant and a binding constant of COSAN, respectively, and $z$ is anion charge. $\beta$ is a portion of the applied voltage which is involved in the translocation process, which means that the ions are located at a certain distance from the membrane-solution interface. Eqn (1) suggests that $\tau$ should be independent of $V$ at low voltage and should decrease exponentially at a high voltage. The curves in Fig. 3B are consistent with this prediction. Table 1 summarizes the values of $k_{i}$ and $\beta$ derived from the fitting of the data of Fig. 3B by eqn (1). We were unable to estimate the values of $k$ because in all cases $k$ was much less than $k_{i}$. The parameter $\beta$ decreased in the series $\mathrm{COSAN} \approx \mathrm{COSAN}-\mathrm{F}_{2}<\mathrm{COSAN}-\mathrm{Cl}_{2}<\mathrm{COSAN}-\mathrm{Br}_{2} \approx \mathrm{COSAN}-\mathrm{I}_{2}$ 
Table 1 Translocation rate constants and fraction of applied voltage for COSAN and its derivatives

\begin{tabular}{lll}
\hline DPhPC & $k_{i}, \mathrm{~s}^{-1}$ & $\beta$ \\
\hline COSAN & 580 & 0.78 \\
COSAN-F & 410 & 0.77 \\
COSAN-Cl $_{2}$ & 7430 & 0.71 \\
COSAN-Br & 10900 & 0.67 \\
COSAN-I $_{2}$ & 15000 & 0.67
\end{tabular}

suggesting a deeper position of $\mathrm{COSAN}-\mathrm{I}_{2}$ and $\mathrm{COSAN}-\mathrm{Br}_{2}$ in the membrane than COSAN.

The translocation could be described as a transfer from one energy well at the membrane-water interface to another across an energy barrier in the interior part of the membrane. It can be noted that the higher value of $k_{i}$ for $\mathrm{COSAN}-\mathrm{I}_{2}$ compared to COSAN was in apparent contradiction with the data of VerdiaBaguena et al. ${ }^{13}$ on the direct measurements of permeabilities of these two compounds through the planar lipid membrane by ICP-MS. Fig. 4 shows the concentration-dependence of the BLM steady-state current induced by COSAN (closed circles) or COSAN-I $\mathrm{I}_{2}$ (open circles). In agreement with Verdia-Baguena et $a .^{13}$ the steady-state current corresponding to ion penetration from one aqueous solution to another was lower in case of COSAN- $\mathrm{I}_{2}$ at concentrations higher than $10 \mu \mathrm{M}$. However, the COSAN-I $\mathrm{I}_{2}$-mediated current was higher than that of COSAN at the lower concentrations (Fig. 4). Because $10 \mu \mathrm{M}$ was shown to be critical concentration of vesicle formation for $\operatorname{COSAN},{ }^{10}$ one can speculate that the aggregation of COSAN-I $\mathrm{I}_{2}$ suppressed the BLM current to a greater extent than that of COSAN. The suppression could be a consequence of the reduced monomer concentration and/or poor interaction of $\mathrm{COSAN}^{-} \mathrm{I}_{2}$ vesicles with the lipid membrane. The process of COSAN-I $\mathrm{I}_{2}$ desorption into the aqueous phase could proceed via the transfer of monomers or as a separation of COSAN- $\mathrm{I}_{2}$ aggregates in the lipid membrane and subsequent vesicle budding. Images of COSAN vesicles penetrating into lipid vesicles have been shown earlier. $^{13}$

The large difference between the rate of translocation of COSAN- $\mathrm{F}_{2}$ and the other halogenated COSAN analogs points to

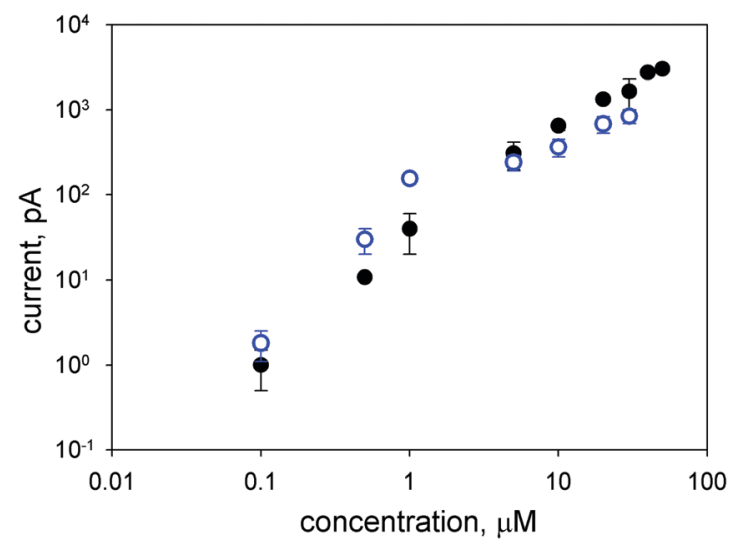

Fig. 4 Steady-state electrical current mediated by COSAN (closed circles) and COSAN- $\mathrm{I}_{2}$ (open circles) at an applied voltage of $5 \mathrm{mV}$. some special feature of COSAN- $\mathrm{F}_{2}$ binding to the lipid membranes. It has been shown earlier that the addition of hydrophobic anion tetraphenylborate (TPB) to liposomes with fluorescent styrylpiridinium dye RH421 led to a shift of the excitation spectrum of fluorescence in the long-wavelength region, ${ }^{23}$ which was associated with the effect of TPB on the membrane potential. Using the dual wavelength ratiometric approach with the voltage sensitive fluorescence probe di-4-ANEPPS ${ }^{24}$ we analyzed the qualitative changes of the lipid membrane potential caused by the adsorption of halogenated COSANs. This dye is more sensitive to changes in the dipole potential and adsorbed faster on the lipid membrane compared with RH421 and di-8-ANEPPS. ${ }^{22,25}$ We assume that under the conditions of excessive lipid concentrations $(1.3 \mathrm{mM})$ over the concentrations of the hydrophobic anions $(<80 \mu \mathrm{M})$ COSAN analogs adsorbed completely on the
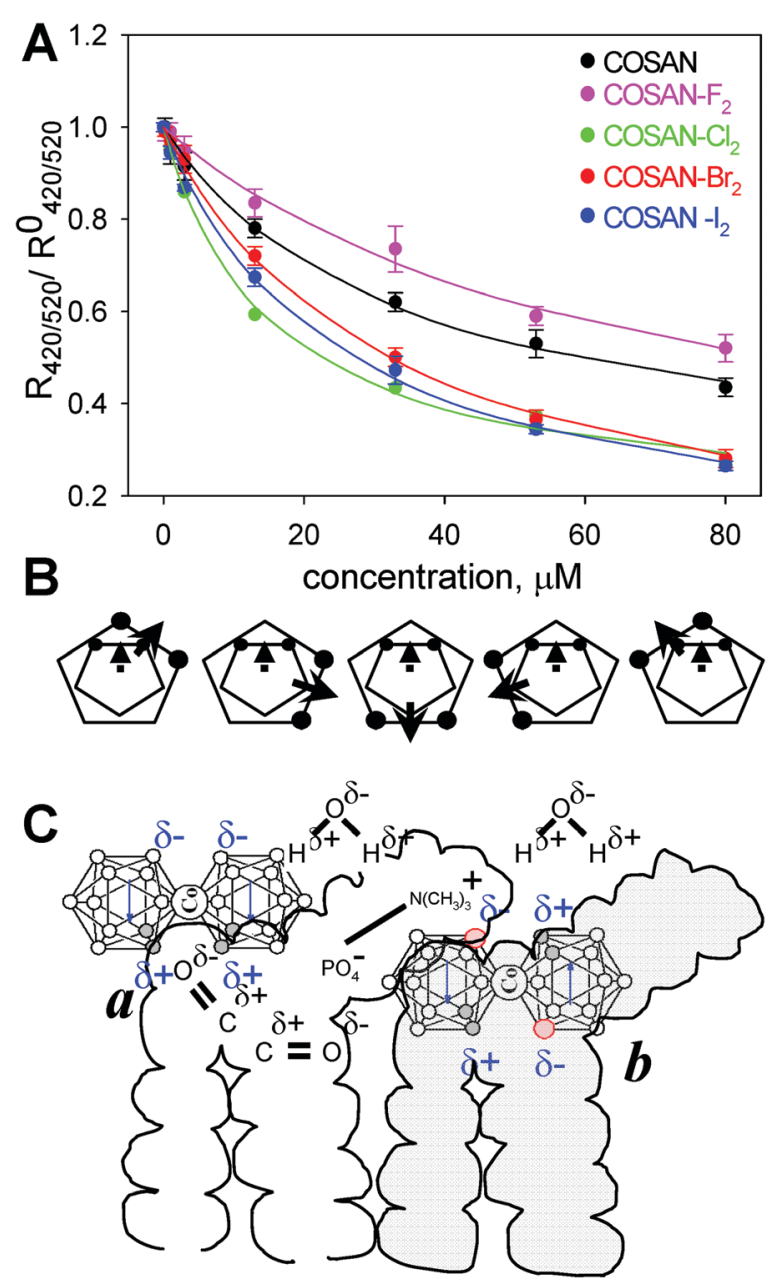

Fig. 5 (A) Fluorescence intensity ratios, $R_{420 / 520}$, normalized to the initial value, of $0.5 \mu \mathrm{M}$ di-4-ANEPPS in the presence of $1.3 \mathrm{mM}$ eggPC as a function of COSAN and derivative concentration. (B) Scheme represents the different conformations for cobalt bis(dicarbollide): cisoid-1, gauche-1, transoid, gauche-2, cisoid-2 (from left to right). The arrows indicate the direction of dipole moments of dicarbollides. (C) Schematic representation of electric dipoles of DPhPC molecules and adjacent water molecules in the lipid bilayer. Adsorbed molecules of COSAN (a) and COSAN- $\mathrm{X}_{2}(\mathrm{X}=\mathrm{Cl}$, $\mathrm{Br}, \mathrm{l})(\mathrm{b})$ in different conformations are presented in the scheme. 
surface of the lipid membrane and that the change of the electrical potential profile in the membrane related to surface potential should be equal for all derivatives. It can be suggested therefore that the variations in the fluorescence ratio for different anions (Fig. 5A) were caused by the different effects of the compounds on the dipole potential of the lipid membrane. Fig. 5A shows the dependence of the fluorescence ratio $\left(R_{420 / 520}\right)$ of the dye di-4-ANEPPS on the concentration of COSAN and its halogenated derivatives. $R_{420 / 520}$ is strongly reduced in the presence of COSAN-Cl ${ }_{2}, \mathrm{COSAN}-\mathrm{Br}_{2}$ and $\mathrm{COSAN}-\mathrm{I}_{2}$ while in the case of COSAN and especially COSAN-F $\mathrm{F}_{2}$ the decrease of $R_{420 / 520}$ was substantially less. The reason for these differences can be based on the differences in the dipole potential of the compounds as well as on the differences in their effects on the dipole potential of the lipid membrane. This point will be further discussed below.

\section{Discussion}

The rate of flip-flop of penetrating ions depends on different factors, such as sign and value of charge, radius of charge delocalization and other features. It has been shown previously that halogenation of tetraphenylborate increased the translocation rate of tetrakis(4-chlorophenyl)borate as well as the fluorinated analog about 1000-fold compared to unsubstituted TPB. ${ }^{15}$ This dramatic effect was accounted for by the smearing of the negative charge across a larger sphere, i.e., the increase of the effective diameter of TPB analogues upon halogenation which should decrease the Born electrostatic component of the transmembrane free energy profile. ${ }^{26}$ In the present study we revealed the following series of the rates of the translocation for halogenated COSAN: COSAN-F ${ }_{2}<$ COSAN $<$ COSAN-Cl $_{2}<$ COSAN-Br $_{2}<$ COSAN-I $_{2}$. In part, this dependence correlates with the increase in the molecular volumes of the halogens that may be essential for the radius of charge delocalization. However, COSAN-F ${ }_{2}$ clearly did not conform to this tendency. Remarkably, the same series was observed in the experiments with the dipole potential sensor di-4-ANEPPS (Fig. 5). This finding points to an involvement of the dipole moment of the compounds in the mechanism of their translocation through the membrane.

The membrane potential of the lipid membrane consists of three major parts: the surface potential, resulting from the accumulation of charge on the membrane interfaces, the transmembrane potential, determined by the imbalance of charge in the aqueous solutions, and the dipolar component, which originates due to the nonrandom arrangements of lipid dipoles and water molecules at the membrane surface. ${ }^{27}$ Several hydrophobic compounds with dipole moments can significantly change the dipole potential of the lipid membrane adsorbing at the lipid bilayer surface. ${ }^{28-30}$ In addition hydrophobic compounds carrying electrical charge can change the surface potential of the membrane in the process of adsorption.

Each of the dicarbollide ligands possesses a significant dipole moment, directed perpendicular to their common axis of rotation in the molecule (scheme in Fig. 5B). The calculated energy difference between the rotational conformers in the case of unsubstituted dicarbollide ligands (COSAN) is not high (approx. 10-12 $\left.\mathrm{kJ} \mathrm{mol}^{-1}\right)^{31}$ allowing their facile interconversion in solution. As a result, the dicarbollide complexes could produce different conformations depending on small external factors. The interaction between the anions and cations observed in the solid state can lead to the stabilization of certain conformations of rotation. A search for COSAN in the Cambridge Structural Database revealed structures containing cisoid conformation (about 80\%,D = 5.4), gauche conformation (about $15 \%, D=3.1$ ) or transoid conformation (about $5 \%$, $D=0)^{32}$ (scheme in Fig. 5B). Introduction of the halogen atoms $\mathrm{X}$ opposite to the carbons position of the pentagonal face of the dicarbollide ligand results in the additional stabilization of the transoid conformation due to formation of the intramolecular hydrogen $\mathrm{C}-\mathrm{H} \cdots \mathrm{X}-\mathrm{B}$ bonds between the dicarbollide ligands. The introduction leads to exclusively transoid conformation for $\mathrm{X}=\mathrm{Br}^{33}$ and $\mathrm{X}=\mathrm{I},{ }^{34,35}$ and preferential transoid (80\%, gauche $20 \%$ ) conformations for $\mathrm{X}=\mathrm{Cl}^{36-39}$ in the solid state. However in the case of $\mathrm{X}=\mathrm{F}\left(\mathrm{COSAN}-\mathrm{F}_{2}\right)$, the $\mathrm{C}-\mathrm{H} \cdots \mathrm{F}-\mathrm{B}$ distances are too long to form the intramolecular hydrogen bonds resulting in the domination of the cisoid conformation in a solid state. ${ }^{19}$

Based on the results shown in Fig. 5A and on the literature data concerning the effects of dipole modifiers on the changes of the fluorescence ratio $\left(R_{420 / 520}\right)$ of di-8-ANEPPS ${ }^{22}$ we can conclude that the binding of COSAN and COSAN-F $\mathrm{F}_{2}$ to liposomes led to an increase in the dipole potential of the lipid membrane. This conclusion is based on the ability of anionic TPB lacking dipole potential to decrease $R_{420 / 520}^{23}$ similar to the effects of COSAN-Cl ${ }_{2}, \mathrm{COSAN}_{-} \mathrm{Br}_{2}$ and COSAN-I ${ }_{2}$. Most likely, the adsorption of COSAN and COSAN-F $F_{2}$ on the lipid membrane favors the preferential cisoid conformation imposed by the electric field of the membrane, and the ordered orientation of their dipole moments should contribute to an increase in the value of the membrane dipole potential (Fig. 5C) similar to 6-ketocholestanol upon its binding. ${ }^{22}$ However, $\mathrm{COSAN}_{-} \mathrm{Cl}_{2}, \mathrm{COSAN}_{-} \mathrm{Br}_{2}$ and COSAN-I could retain a transoid conformation upon adsorption on the lipid membrane (Fig. 5C). Possibly, the differences in the reside depth of the anions in the hydrophobic layer of the lipid phase (parameter $\beta$, Table 1) can also be related to the presence/absence of the dipole moment of the anions. The slowing of the translocation rate of COSAN-F $F_{2}$ compared to COSAN could be attributed to several factors. One of them could be the increase of the dipole moment of the fluorinated analogue due to the high electronegativity of fluorine. Also, fluorination leads frequently to an increase in hydrophobicity ${ }^{40}$ as was in the case for the fluorinated derivative of the anionic tungsten carbonyl complex $\left[\mathrm{W}\left(\mathrm{CO}_{5}\right) \mathrm{SC}_{6} \mathrm{H}_{5}\right]^{-} \cdot{ }^{41}$ Interestingly, the fluorination of the phenyl ring in this anionic complex led to a slowing of its translocation across the lipid membrane by at least one order of magnitude. ${ }^{41}$

The presence of the dipole moment of the anion COSAN localized on the surface of the lipid membrane (Fig. 5C) should provide an additional potential barrier to penetration through the membrane compared to the analogs lacking a dipole moment because the process of penetration must include a stage of reorientation of its dipole. It has been shown recently that the 
orientation of anion carriers (dithioureido decalins) at the membrane surface contributes significantly to the rate of chloride permeation through the lipid membrane. ${ }^{42}$ The bound transporter and chloride complex oriented their polar regions towards the membrane interface and are able to exhibit effective polar interactions with the phospholipid head groups or with bound water molecules. These polar interactions must be broken before the transporter/complex can pass through the membrane, and therefore contribute a substantial potential barrier to the translocation. Recently, the role of orientational and conformational motion in the process of passive transbilayer diffusion of the solutes $^{43}$ and steroids ${ }^{44}$ has been pointed out.

It is well known, that the increase of the dipole potential of the lipid membrane promotes the translocation of hydrophobic anions. ${ }^{45}$ From this point of view, one would expect that the rates of translocation of COSAN and COSAN- $\mathrm{F}_{2}$ should be higher than for other halogenated analogues (Fig. 5). However, it can be suggested that the concentrations of anions in the experiments on current relaxation were too small (100 nM in aqueous solution) to form a regular layer of oriented dipoles on the membrane surface. In fact, the number of COSAN in one monolayer was about $N_{\mathrm{COSAN}}=Q / e \approx 1 \mathrm{nC} / 1.6 \times 10^{-19} \mathrm{C} \approx 6 \times$ $10^{9}$ ( $e$ - the charge of the electron), while the number of the lipid molecules was $N_{\text {lipid }}=5 \times 10^{13} \AA^{2} / 60 \AA^{2} \approx 10^{12}$ (the area of BLM was $S=\pi R^{2}=\pi \times(0.4 \mathrm{~mm})^{2} \approx 0.5 \mathrm{~mm}^{2}=5 \times 10^{13} \AA^{2}$, and the area per lipid molecules was $\left.60 \AA^{246}\right)$. Therefore, the number of COSAN anions adsorbed on the lipid membrane was more than two orders of magnitude lower than the lipid molecules suggesting their minor contribution to the dipole potential of the membrane.

Thus, we found that the rate of flip-flop of most halogenated derivatives of COSAN increased with increasing molecular weight of the halogen and the volume of the penetrating anion. In contrast, the fluorinated derivative exhibited slowing down of transmembrane penetration. We hypothesize that these analogs acquire a dipole moment in the process of adsorption on the surface of the lipid membrane which complicates the permeation due to the rotational component of the transmembrane diffusion. Further work is required to confirm or deny the role of the dipole potential in the mechanisms of COSAN penetration through lipid membranes. In general, the understanding of the mechanism of the drug permeation through lipid membranes could promote work on the increase of bioavailability of different therapeutic compounds. For example, conjugates of COSAN with synthetic and natural porphyrins are studied in relation to the photodynamic and boron neutron capture therapy (BNCT) of tumors. ${ }^{47-49}$ of note, the rate of the flip-flop of COSAN and its analogs were substantially faster compared to the tetraphenylborate anion and its derivatives. ${ }^{4,15,50}$

\section{Abbreviations}

$\begin{array}{ll}\text { COSAN } & \text { Cobalt bis(dicarbollide) } \\ \text { COSAN-F } & \text { Fluorinated cobalt bis(dicarbollide) } \\ \text { COSAN-Cl } & \text { Chlorinated cobalt bis(dicarbollide) }\end{array}$

COSAN-Br ${ }_{2} \quad$ Brominated cobalt bis(dicarbollide)

COSAN-I ${ }_{2} \quad$ Iodinated cobalt bis(dicarbollide)

BLM Bilayer lipid membrane

DPhPC Diphytanoylphosphatidylcholine

TPB Tetraphenylborate

\section{Conflicts of interest}

There are no conflicts of interest to declare.

\section{Acknowledgements}

The authors are grateful to Dr Galina Korshunova and Dr Elena Kotova for help in the present work and fruitful discussions. This work was supported in part by the Russian Foundation for Basic Research grants 15-04-01688, 15-04-01755 and 16-03-00724.

\section{References}

1 E. A. Liberman and V. P. Topaly, Biochim. Biophys. Acta, 1968, 163, 125-136.

2 O. H. LeBlanc, Biochim. Biophys. Acta, 1969, 193, 350-360.

3 B. Ketterer, B. Neumcke and P. Lauger, J. Membr. Biol., 1971, 5, 225-245.

4 O. S. Andersen and M. Fuchs, Biophys. J., 1975, 15, 795-830.

5 M. F. Hawthorne and G. B. Dunks, Science, 1972, 178, 462-471.

6 I. B. Sivaev and V. I. Bregadze, Collect. Czech. Chem. Commun., 1999, 64, 783-805.

7 A. Popov and T. Borisova, J. Colloid Interface Sci., 2001, 236, 20-27.

8 P. M. Gassin, L. Girard, G. Martin-Gassin, D. Brusselle, A. Jonchere, O. Diat, C. Vinas, F. Teixidor and P. Bauduin, Langmuir, 2015, 31, 2297-2303.

9 P. Matejicek, P. Cigler, K. Prochazka and V. Kral, Langmuir, 2006, 22, 575-581.

10 M. Uchman, V. Dordovic, Z. Tosner and P. Matejicek, Angew. Chem., Int. Ed., 2015, 54, 14113-14117.

11 C. Vinas, M. Tarres, P. Gonzalez-Cardoso, P. Farras, P. Bauduin and F. Teixidor, Dalton Trans., 2014, 43, 5062-5068.

12 P. Bauduin, S. Prevost, P. Farras, F. Teixidor, O. Diat and T. Zemb, Angew. Chem., Int. Ed., 2011, 50, 5298-5300.

13 C. Verdia-Baguena, A. Alcaraz, V. M. Aguilella, A. M. Cioran, S. Tachikawa, H. Nakamura, F. Teixidor and C. Vinas, Chem. Commun., 2014, 50, 6700-6703.

14 M. Tarres, E. Canetta, E. Paul, J. Forbes, K. Azzouni, C. Vinas, F. Teixidor and A. J. Harwood, Sci. Rep., 2015, 5, 7804.

15 R. Benz, Biophys. J., 1988, 54, 25-33.

16 G. B. Melikyan, B. N. Deriy, D. C. Ok and F. S. Cohen, Biophys. J., 1996, 71, 2680-2691.

17 T. I. Rokitskaya, S. S. Klishin, I. I. Severina, V. P. Skulachev and Y. N. Antonenko, J. Membr. Biol., 2008, 224, 9-19.

18 M. F. Hawthorne, D. C. Young, T. D. Andrews, D. V. Howe, R. L. Pilling, L. F. Warren Jr. and P. A. Wegner, J. Am. Chem. Soc., 1968, 90, 879-896. 
19 A. N. Gashti, J. C. Huffman, A. Edwards, G. Szekeley, A. R. Siedle, J. A. Karty, J. P. Reilly and L. J. Todd, J. Organomet. Chem., 2000, 614-615, 120-124.

20 L. Matel, F. Macásek, P. Rajec, S. Heřmánek and J. Plešek, Polyhedron, 1982, 1, 511-519.

21 P. Mueller, D. O. Rudin, H. T. Tien and W. C. Wescott, J. Phys. Chem., 1963, 67, 534-535.

22 R. J. Clarke and D. J. Kane, Biochim. Biophys. Acta, 1997, 1323, 223-239.

23 R. J. Clarke, A. Zouni and J. F. Holzwarth, Biophys. J., 1995, 68, 1406-1415.

24 L. M. Loew, L. B. Cohen, J. Dix, E. N. Fluhler, V. Montana, G. Salama and J. Y. Wu, J. Membr. Biol., 1992, 130, 1-10.

25 V. S. Sokolov, A. N. Gavrilchik, A. O. Kulagina, I. N. Meshkov, P. Pohl and Y. G. Gorbunova, J. Photochem. Photobiol., B, 2016, 161, 162-169.

26 A. Parsegian, Nature, 1969, 221, 844-846.

27 L. G. Wang, Annu. Rev. Biochem., 2012, 81, 615-635.

28 O. S. Andersen, in Renal Function, ed. G. H. Giebisch and E. F. Purcell, Josiah Macy, Jr. Foundation, New York, 1978, pp. 71-99.

29 P. Pohl, T. I. Rokitskaya, E. E. Pohl and S. M. Saparov, Biochim. Biophys. Acta, 1997, 1323, 163-172.

30 J. C. Franklin and D. S. Cafiso, Biophys. J., 1993, 65, 289-299.

31 M. Buhl, D. Hnyk and J. Machacek, Chem. - Eur. J., 2005, 11, 4109-4120.

32 E. J. Juarez-Perez, R. Nuriez, C. Vinas, R. Sillanpaa and F. Teixidor, Eur. J. Inorg. Chem., 2010, 2385-2392.

33 O. Kazheva, G. Alexandrov, A. Kravchenko, V. Starodub, I. Lobanova, I. Sivaev, V. Bregadze, L. Buravov and O. Dyachenko, Solid State Sci., 2008, 10, 1734-1739.

34 P. Sivý, A. Preisinger, O. Baumgartner, F. Valach, B. Koren and L. Matel, Acta Crystallogr., Sect. C: Cryst. Struct. Commun., 1986, 42, 28-30.

35 O. N. Kazheva, G. G. Alexandrov, A. V. Kravchenko, V. A. Starodub, I. A. Lobanova, I. B. Sivaev, V. I. Bregadze, L. V. Titov, L. I. Buravov and O. A. Dyachenko, J. Organomet. Chem., 2009, 694, 2336-2342.
36 N. I. Kirillova, A. S. Zhdanov, A. I. Gusev, V. N. Kirin, S. P. Knyazev and T. V. Sokolova, Organomet. Chem. USSR, 1989, 2, 448-450.

37 P. K. Hurlburt, R. L. Miller, K. D. Abney, T. M. Foreman, R. J. Butcher and S. A. Kinkhead, Inorg. Chem., 1995, 34, 5215-5219.

38 O. N. Kazheva, A. V. Kravchenko, G. G. Alexandrov, I. B. Sivaev, V. I. Bregadze, I. D. Kosenko, I. A. Lobanova and L. I. Buravov, Russ. Chem. Bull., 2014, 63, 1322-1329.

39 O. N. Kazheva, G. G. Alexandrov, A. V. Kravchenko, I. B. Sivaev, V. A. Starodub, I. D. Kosenko, I. A. Lobanova, V. I. Bregadze, L. I. Buravov and O. A. Dyachenko, J. Chem. Eng. Chem. Res., 2015, 2, 497-503.

40 M. P. Krafft and J. G. Riess, Biochimie, 1998, 80, 489-511.

41 M. Kurschner, K. Nielsen, J. R. G. von Langen, W. A. Schenk, U. Zimmermann and V. L. Sukhorukov, Biophys. J., 2000, 79, 1490-1499.

42 S. J. Edwards, I. Marques, C. M. Dias, R. A. Tromans, N. R. Lees, V. Felix, H. Valkenier and A. P. Davis, Chem. Eur. J., 2016, 22, 2004-2011.

43 G. Parisio, M. Stocchero and A. Ferrarini, J. Chem. Theory Comput., 2013, 9, 5236-5246.

44 G. Parisio, M. M. Sperotto and A. Ferrarini, J. Am. Chem. Soc., 2012, 134, 12198-12208.

45 E. A. Liberman and V. P. Topaly, Biofizika, 1969, 14, 452-461.

46 B. A. Cornell, J. Middlehurst and F. Separovic, Biochim. Biophys. Acta, 1980, 598, 405-410.

47 E. Hao, T. J. Jensen, B. H. Courtney and M. G. Vicente, Bioconjugate Chem., 2005, 16, 1495-1502.

48 P. Kubat, K. Lang, P. Cigler, M. Kožišek, P. Matejiček, P. Janda, Z. Zelinger, K. Prochazka and V. Kral, J. Phys. Chem. B, 2007, 111, 4539-4546.

49 A. V. Efremenko, A. A. Ignatova, M. A. Grin, I. B. Sivaev, A. F. Mironov, V. I. Bregadze and A. V. Feofanov, Photochem. Photobiol. Sci., 2014, 13, 92-102.

50 D. Y. Malkov and V. S. Sokolov, Biochim. Biophys. Acta, 1996, 1278, 197-204. 